ARCHIVOS

de historia del movimiento obrero y la izquierda
ISSN 2313-9749

ISSN en línea 2683-9601

Año VIII, $\mathrm{n}^{\circ} 16$, pp. 113-133

marzo de 2020-agosto de 2020

\title{
Buenos Aires negro: la experiencia afroporteña y debates historiográficos en los orígenes de la clase obrera y el socialismo argentino, 1873-1882
}

\author{
Lucas Glasman \\ Universidad de Buenos Aires - Centro de Estudios Históricos de los Trabajadores y las Izquierdas \\ (Buenos Aires, Argentina) • lucas.glasman@gmail.com
}

Titulo: Black Buenos Aires: The experience of Afroporteños and historiographical debates on the origins of the Argentine working class and socialism, 1873-1882

Resumen: Este artículo examina la relación entre la población afroporteña, la clase obrera en formación y el desarrollo del socialismo en Argentina entre 1873 y 1882. Generalmente los estudios acerca de la comunidad afroporteña han abordado esta relación superficialmente, mientras que la historiografia de los orígenes de la clase obrera se ha enfocado en el impacto de la inmigración. A partir del análisis de los periódicos afroporteños buscamos reconstruir la vida asociativa negra, sus organizaciones y su cultura.

Palabras clave: clase obrera - socialismo - afroporteños - negritud

Abstract: This article explores the relationship between Buenos Aires' afro population, the working class in the making and the emerging socialism in Argentina in 1873-1882. Generally, research on the afro community has superficially approached the subject matter, while the historiography on the origins of the working class has focused on the impact of the immigration. Based on the analysis of the afroporteños newspapers we aim to recreate their social life, clubs and organizations and their culture.

Keywords: working class - socialism - afroporteños - nlack culture

Recepción: 3 de noviembre de 2019. Aceptación: 27 de febrero de 2020 
En 1881 José Antonio Wilde publicó un libro con sus observaciones sobre la ciudad de Buenos Aires en el que concluia: "Hoy los negros son relativamente escasos. Se ve acá y allá algún veterano como representante de la raza que se va: un monumento que el tiempo ha carcomido" (Wilde, 1960, p. 124). A su vez, el autor pronosticaba que el fin del siglo inauguraria una nueva era para la Argentina. Las rebeliones federales eran un espectro del pasado, los caudillos habían sido derrotados y ni siquiera Buenos Aires había podido enfrentarse al ejército nacional. En paralelo, las campañas hacia las tierras indígenas del sur patagónico habian efectivizado un genocidio que reunió enormes extensiones de tierras en las manos de unos pocos terratenientes. Por último, desde el Estado se había incentivado la inmigración europea. La clase obrera "importada" desde Europa -laboriosa, culta y blanca- debía desplazar al gaucho, al indígena y al negro y finalizar el proceso de erradicación de las tradiciones locales, que veía como barbáricas e incompatibles con el mundo moderno y las relaciones sociales capitalistas. Esa era, en gran medida, la esperanza de Wilde y otros representantes de la generación del 80.

Empero, se equivocaban. No solo la inmigración trajo una cultura de organización y lucha, sino que las tradiciones locales no fueron eliminadas. El nacimiento de una clase obrera enmarcada en una serie de relaciones sociales crecientemente capitalistas es un proceso complejo. Diversas raíces nutrieron este proceso directa o indirectamente: tradiciones políticas, ideologias, cosmovisiones, identidades, prácticas culturales, experiencias y herramientas influyeron en el largo proceso por el cual se formó la clase obrera local. Usualmente la historiografia ha destacado el rol que la inmigración europea jugó -tanto por su enorme caudal como por sus experiencias de lucha y organización- en los orígenes de la clase obrera. En cambio, las tradiciones locales previas permanecieron, en gran medida, inexploradas. Estas no se desvanecieron, sino que son las raíces que forman parte de los orígenes perdidos de la clase obrera en Argentina.

En este trabajo analizaremos una de estas tradiciones olvidadas: la experiencia afro en Buenos Aires de la década de 1870 y los primeros años de la siguiente. Este recorte temporal nos permite, por un lado, cuestionar la idea de la desaparición de la población afro en la Argentina y, por el otro, enriquecer la historia de los trabajadores y las izquierdas en una época que aún no ha sido explorada sistemáticamente.

La historia de los afroporteños ocupa un lugar privilegiado en la historia obrera, tanto por su nutrida vinculación con el mundo y las identidades proletarias como así también porque nos obliga a repensar nuestras categorias de análisis a fin de incorporar sectores olvidados por gran parte de la historiografia. 
Para el estudio de la experiencia de los trabajadores negros de Buenos Aires nos parece relevante tener en cuenta dos historiografias muy diferentes entre sí pero que mantienen algunos contactos: en principio haremos un recorrido por la historiografia sobre los origenes del movimiento obrero y las izquierdas y después nos acercaremos a las diversas corrientes que tratan la historia de los afroporteños.

\section{Clase obrera, izquierdas y sectores populares en la historiografía argentina}

Entre las primeras producciones que se ocupan de los origenes del movimiento obrero y las izquierdas nos encontramos con las pioneras "historias militantes" (Abad de Santillán, 1930; Oddone, 1949; Marotta, 1960) que, si bien aportan testimonios y documentación muy valiosa, suelen caer en relatos apologéticos donde pareciera que, previo a la aparición de sus organizaciones, la historia de los trabajadores en la Argentina era un desierto, con unos pocos oasis como la huelga tipográfica de 1878. Los años dotaron a la historiografia del movimiento obrero y las izquierdas un perfil cada vez más profesional. Entre los años 70 y 80, adquirieron especial relevancia los trabajos de Julio Godio (1987) y Ricardo Falcón (1984) referidos específicamente a los origenes del movimiento obrero en el país. La obra de Falcón se distingue por prestar mayor interés a las décadas entre 1850 y 1880 donde todavia priman los artesanos, jornaleros y trabajadores no especializados. Entre sus hallazgos se encuentran varios periódicos de la comunidad afro en el país que aparecen vinculados al movimiento obrero y al socialismo. Si bien Falcón se interesa por la relación entre la población negra, el movimiento obrero y el socialismo, los considera un sector incapaz de organizarse autónomamente (Falcón, 1984, p. 15). Por su parte, Godio al analizar las huelgas de tipógrafos de 1878 y cigarreros de 1879 , no le otorga ningún tipo de relevancia al movimiento afro a pesar de que este participó - directa o indirectamente- de ambas medidas de fuerza. Finalmente, a partir del 2000, han surgido nuevos trabajos que también han analizado los orígenes del movimiento obrero y las izquierdas en Argentina. Se destacan la tesis de Lucas Poy (2014) sobre los origenes del movimiento obrero, analizando el ciclo huelguístico iniciado en 1888, y las obras de Horacio Tarcus $(2007,2016)$ sobre el desarrollo del socialismo romántico y utópico, como también la recepción de Marx en el país.

Vemos así que la historiografia del movimiento obrero y las izquierdas se ha centrado, generalmente, en los periodos más próximos al final del siglo o bien en el desarrollo de las ideologias. Este recorte ha hecho que elementos con mayor presencia en años anteriores -como la etnia o las formas de trabajo hibridas- tiendan a ocupar un lugar secundario. Existe otra gama de historiadores profesionales que, para analizar la 
heterogeneidad de situaciones han buscado alternativas al concepto de clase obrera. Autores como Raúl Fradkin (2008) o Gabriel Di Meglio (2001) utilizaron los conceptos de sectores subalternos o plebe urbana cuya amplitud permite incorporar elementos tan constitutivos como la etnia o la ascendencia para analizar los principios del siglo XIX.

Por otra parte, otros investigadores como Ezequiel Adamovsky (2012) establecen un recorte temporal más amplio, abarcando el final del siglo XIX, utilizando el concepto de clases populares. Esto le facilita al autor incorporar elementos como la etnia al análisis. Al estudiar a los afroargentinos, Adamovsky se centra en el proceso de asimilación de la población afro a la sociedad blanca. Menciona la existencia de tensiones internas en donde la identidad obrera y las luchas de esta comunidad quedan subsumidas en un contexto más amplio.

Asimismo, hubo una tradición comenzada y encarnada por Luis Alberto Romero y Leandro Gutiérrez y, posteriormente, Juan Suriano, quienes rechazaron el concepto de clase por su rigidez, por su carácter foráneo "insular" (Gutiérrez y Romero, 1990, p. 270) o, en el caso de Suriano, argumentando que el paso del tiempo y la movilidad social permitirian que la identidad obrera se diluyera (Suriano, 2001, p. 340).

Así, se nos presenta una laguna historiográfica atravesada por los debates conceptuales que se plantean entre quienes utilizan el concepto de clase obrera y los que abogan por el de sectores populares. En el último tiempo ha comenzado un dialogo entre la historiografia de principios de siglo y la del movimiento obrero que busca superar esta laguna incorporando las historias olvidadas, tensionando categorias y recortes temporales. De esta forma se busca reconstruir las heterogéneas raíces de la clase trabajadora, sus luchas y tradiciones sin diluir la identidad de clase (Mitidieri y Poy, 2019, p. 10).

Creemos que el análisis del movimiento afroporteño puede ser un aporte útil en este debate. De igual modo, los estudios referidos a la población afroargentina permiten repensar este periodo de la historia introduciendo categorías de análisis nuevas.

\section{Negritud y clase obrera en la historiografía afroargentina}

A fines de 1980, en consonancia con el ocaso de los estudios de clase, comienzan a cobrar relevancia los estudios de sectores subalternos específicos. Sin duda, los trabajos del estadounidense George Reid Andrews (1989, 2007, 2010, 2016) fueron un pilar fundacional en el campo de estudios afroargentinos. Su libro "Los afroargentinos de Buenos Aires" busca rebatir los argumentos clásicos en torno a la "desaparición" de la población afrodescendiente y el blanqueamiento argentino. El autor remonta su análisis al siglo XVIII considerando el 
comercio de esclavos, el lugar de los negros en la sociedad, su rol en las guerras y la transición a la libertad, a fin de demostrar que estos no fueron factores explicativos del descenso demográfico que muestran los censos. Utilizando fuentes no estadísticas, Andrews examina la constante presencia de la población negra y sus organizaciones a través de los años. Recurriendo a fuentes periodísticas, lecturas bajo otro prisma de los censos y la prensa afroporteña, el autor logra cuestionar los datos censales que, por sus imprecisiones, sirvieron de base para retratar a una Argentina étnicamente blanca.

Por su parte, Alejandro Frigerio $(2006,2008)$ ha examinado la construcción de la "narrativa" de la Argentina como nación blanca. Profundizando sobre las conclusiones de Andrews, Frigerio se propone entonces repensar las categorias de "negritud" y "blanquitud" donde el primero tiene un carácter excluyente -solo es negro quien posee todos sus rasgos- mientras que el segundo es demasiado inclusivo -caucásico, trigueños, mulatos, mestizos-. El autor explica que este binomio tuvo la función de crear un relato en la Argentina que niega cualquier influencia de la población africana en la identidad nacional. En este mismo sentido perfilan los trabajos de Alejandro Solomianski (2003, 2012) quien indaga los discursos racistas que construyen el binomio blanquedad-negritud en los origenes de la identidad argentina. A través del análisis cultural, el autor logra identificar las tensiones en la comunidad afro donde el racismo se infiltra con una impronta nacionalista. Posteriormente, autores como Jean-Arsène Yao (2015), también examinaron la contradicción presente en la prensa afroporteña donde, por un lado, se enorgullecian de su condición étnica y denunciaban la discriminación, pero, por el otro, censuraban sus tradiciones afro para someterse a las normas de sociabilidad blancas.

La historia cultural ha sido, desde un principio, parte importante de la historiografia afro. Autores clásicos como Bernardo Kordon (1938) han sido verdaderos pioneros que, a través de sus estudios sobre el tango y el candombe, han echado luz a las problemáticas que atravesaban a la comunidad, como la apropiación de sus festividades por parte de los blancos. Más recientemente, autores como Norberto Cirio (2006) y Laura López (2006) han analizado el tango, el candombe y diversos estilos musicales para reconstruir la identidad afroporteña.

Al examinar el caso puntual de los afroporteños a fines del siglo XIX, nos encontramos con la obra de Norberto Cirio (2009) sobre los periódicos de la comunidad negra. Si bien no indaga directamente en la relación con el mundo obrero o las izquierdas, el trabajo logra recuperar las voces de los afroporteños enfocándose en la estructura y los tópicos de los semanarios para reconstruir las identidades etarias, étnicas y de clase. 
Finalmente, encontramos los varios trabajos del Grupo de Estudios Afrolatinoamericanos (GEALA). Discutiendo la idea de la Argentina como una nación "blanca" y "europea", han dedicado trabajos sobre la importancia social de la población afro, la esclavitud y las guerras en los inicios del siglo XIX (Guzmán, 2006) como también análisis de poblaciones específicas en distintos puntos del país (Marta Maffia, 2016). Particularmente Lea Geler ha escrito numerosas obras centradas en la población afroporteña de fines de siglo XIX (2007, 2008, 2010, 2012). La gran producción de esta autora se destaca por su carácter minucioso, sistemático y plural que le permite abordar varias temáticas tales como el género, el periodismo, la política, entre otros temas. Si bien no deja de mencionar la condición de los negros como trabajadores ni sus luchas, se priorizan otros elementos como la movilidad social o conflictos internos. Así, las conclusiones de Geler contrastan completamente con las extraídas por Falcón. La autora rescata la gran importancia y vitalidad de la población afro, pero en su análisis la relación con la formación de la clase obrera y las izquierdas ocupa un lugar subordinado (Geler, 2010, p. 268), mientras que para Falcón la relación entre el mundo negro y las izquierdas era estrecha pero, en última instancia, estéril.

Nos parece necesario hacer un breve balance acerca de las historiografias presentadas. Dentro de la historia de los orígenes del movimiento obrero y las izquierdas, los componentes que dotan de heterogeneidad a la clase obrera -como la etnia, el género o, también, las formas hibridas de trabajo- han sido subrepresentadas y subanalizadas. Por su parte, quienes abonan los análisis sobre los afroporteños como parte de los sectores populares o los examinan aisladamente, no abordan específicamente la importancia de esta experiencia en los ámbitos obreros y en la historia de las izquierdas. Queda planteado así un problema sobre la situación de los trabajadores afro en particular, pero también una problemática historiográfica general. El siglo XIX comienza con una plebe urbana heterogénea que tras la caída de Rosas parece sumergirse en un letargo para despertar recién a fines de la década de 1880. Empero, sus ropajes han cambiado, su color de piel también, su acento, su procedencia, sus tradiciones y su denominación. Surge entonces una incógnita: ¿qué ocurrió en esos 30 años?

Creemos que la historia de los afroporteños puede aportar elementos para contestar esta pregunta y, a la vez, hacer un aporte al debate historiográfico vigente. Para esto analizaremos tres ejes en particular: las condiciones de vida de los afroporteños y sus redes de sociabilidad; las luchas de la comunidad y su relación con el socialismo y, por último, la cultura como espacio de resistencias y tensiones internas. Buscamos así revalorizar un sector del proletariado que ha quedado olvidado pero 
cuyas raíces están arraigadas en los orígenes de la clase obrera y la izquierda Argentina.

\section{Los semanarios afroporteños: periodismo negro y obrero en la esfera liberal}

El derrocamiento de Juan Manuel de Rosas en 1852 permitió que una gran variedad de publicaciones, antes perseguidas o censuradas, irrumpieran en la escena política, social y cultural. En general, la libertad de expresión que los intelectuales pregonaban se encontraba bastante restringida a una serie de valores e ideas de talante liberal, republicano y positivista (Lettieri, 2005, p. 103). Particularmente, aquellos sectores que habian estado vinculados al rosismo -como los afroporteños- se encontraron bajo tela de juicio. A pesar del ámbito desfavorable, la comunidad negra comprendió la importancia de la palabra escrita y proliferaron las publicaciones que, hoy dia, se convirtieron en nuestra principal fuente. Si bien sabemos de la existencia de, al menos, una docena de publicaciones afro, no todas se conservaron. ${ }^{1} \mathrm{El}$ núcleo de nuestra investigación corresponde a los centenares de números de $L a$ Broma y La Juventud, los dos principales periódicos de noticias generales, asimismo contamos varios ejemplares de otros semanarios como La Perla, La Igualdad, El Unionista y El Aspirante que nos ayudan a dimensionar el tamaño de esta comunidad ilustrando nuevos debates y puntos de vista diversos que enriquecen el análisis. Este corpus nos permite reconstruir la dinámica de la sociabilidad afroporteña entre los años 1873 y 1882 . Asimismo, contamos con unos pocos ejemplares de El Proletario de 1858, fundado por Lucas Fernández. Este semanario inauguró el ciclo de periódicos hechos por afrodescendientes y muchas de sus ideas y temáticas fueron heredadas por los semanarios posteriores (Corbière, 2003).

Las revistas analizadas mantienen ciertas regularidades entre sí. Cada número estaba conformado por cuatro carillas. La primera plana se ocupaba en los títulos, notas editoriales o referidas a algún conflicto en la comunidad. Generalmente, estas eran reflexiones en torno a la discriminación, la sociedad, el trabajo o, en ocasiones, notas de carácter pedagógico y moralizante sobre la vida y la familia. En las páginas interiores se extendía una sección cultural titulada variedades o "varillazos". Probablemente esta era la sección más popular de cada periódico, en ella abundaban noticias sobre la comunidad afroporteña: historias de bailes y tertulias, aventuras amorosas; publicaban cuentos, poesías y

1. Algunos de estos periódicos son La Voz del Obrero, La Simpatía, El Arte en Plata, El Artesano (también conocido como El Tambor), La Cotorra, El Trabajo: órgano de las clases obreras, La Estrella Polar o El Progreso, entre otros. 
canciones, algunas de ellas interpretadas por las comparsas durante el carnaval. Acompañando a estas noticias encontramos chistes, rumores y noticias breves de tono jocoso. Es destacable que la sección de variedades se destinaba, específicamente, al público femenino, dando un indicio de la relevancia de las mujeres para estas publicaciones. Lejos de ser lectoras pasivas, ellas redactaban notas, cuentos, poesías e, incluso, tomaban posición en los debates que se erguian entre los semanarios. Sin embargo, los hombres ocupaban siempre los puestos directivos en las redacciones de los periódicos. Finalmente, la última página contenía novedades sobre colectas, reuniones y promociones de tertulias. En ocasiones, esta página también era utilizada como espacio publicitario para individuos o negocios que, por un canon, promocionaban sus servicios. Es destacable que también se utilizaban los anuncios para promocionar las redes de la sociabilidad afro.

Existian diferencias notorias entre los semanarios. Las opiniones en torno a temáticas como la educación o las opiniones sobre las diferentes mutuales hacian que cada publicación se diferencie de la otra, esto permitía que la prensa afroporteña sea un espacio de discusión y debates abierto, aunque no siempre cordial. Sin embargo, la distinción más notable se da en el caso de La Igualdad y El Artesano, en tanto se erguian como periódicos netamente partidarios apoyando las candidaturas de Nicolás Avellaneda y Bartolomé Mitre, respectivamente. En estos semanarios la mayor parte del espacio se dedicaba a notas políticas, la sección de variedades ocupaba un rol subordinado y, muchas veces, las anécdotas y chistes incluían un mensaje partidario. Asimismo, estas publicaciones eran financiadas enteramente por los partidos políticos, mientras que aquellos periódicos de "interés general" como La Broma o La Juventud dependian de ventas, colectas y aportes de miembros de la comunidad. Tras las elecciones de 1874, estos periódicos dejaron de publicarse. Como resultado, La Igualdad y El Artesano eran vistas como revistas ajenas a los intereses de la comunidad y que representaban, únicamente, a los partidos políticos que buscaban conseguir el voto de los afroporteños.

Finalmente, para terminar con la descripción, queremos destacar un elemento más sobre los semanarios: el precio. Para alcanzar a un público trabajador y, particularmente entre los afrodescendientes, pobre el costo del periódico no podía ser muy elevado. La prensa afro tenía un precio que oscilaba entre los 2 y 5 pesos cada número en Buenos Aires. Según algunas notas de los periódicos y datos oficiales, los sueldos diarios para los varones rondaban los 600 pesos mensuales, a lo que se sumaba el sueldo femenino. Considerando que los gastos en comida y 
renta representaban unos 400 pesos, ${ }^{2}$ las familias trabajadoras negras podian dedicar parte de sus ingresos a la compra de algunos periódicos, asociarse a alguna mutual y también aportar en las colectas. El precio accesible de las publicaciones respondía a que eran un producto hecho por y para obreros y obreras, particularmente, afrodescendientes. Ocasionalmente alguna organización, como la mutual Sociedad Esperanza Argentina, exigía elevados aportes para ingresar a la misma excluyendo a toda la capa de trabajadores afro. En respuesta, se activaron los mecanismos de presión en la comunidad. La indignación de varias personas se cristalizó en el semanario La Juventud, ${ }^{3}$ que se convirtió en una tribuna de repudio ante la apatía de la mutual frente a la miseria obrera. Finalmente, Sociedad Esperanza Argentina fue objetivo de un boicot en 1876 que dio como resultado la deslegitimación de la asociación mutual. La comunidad trabajadora afroporteña entendía que un importe desmesurado atentaba contra la posibilidad de construir una red de sociabilidad que aglutinara a la población afrodescendiente y reaccionaban en consecuencia. Estas medidas de fuerza contra la exclusión del empobrecido proletario es una clara muestra de la preocupación por las problemáticas que afectaban a la clase obrera. El germen de estas prácticas estaba en la autopercepción de los afroporteños como trabajadores.

\section{Trabajadores afro: la vida obrera y la sociabilidad afroporteña}

La vida de los afrodescendientes en Buenos Aires era dura. En los primeros años de la década de 1860 se asentaron prontamente en los conventillos de San Telmo y Monserrat (Andrews, 1989, p. 95). Con la llegada de los contingentes europeos, muchos se desplazaron hacia zonas del sur y el oeste de la ciudad como Barracas, Socorro, Concepción, San Nicolás, entre otras. Las habitaciones podían llegar a albergar a más de 10 personas, por lo que el hacinamiento era parte de la vida cotidiana (Bourdé, 1977, p. 89). Afuera, los vecinos adoquinaban las calles con piedras del riachuelo y las rellenaban con basura que rebalsaba a menudo (Mafud, 1976, p. 179). Bajo estas condiciones no es sorprendente que las barriadas obreras se hayan convertido en focos de infecciones y enfermedades como el cólera o la fiebre amarilla. Aun así, los precios de los alquileres junto a la comida eran muy elevados, por lo que toda la familia debía salir en busca de empleo. La mayor parte de los hombres y mujeres de la comunidad afroporteña solian trabajar ya fuese brindando servicios de forma individual (músicos, hojalateros, costureras,

2. "El hombre del pueblo", La Juventud, 26 de marzo 1876.

3. "Consejos sociales", La Juventud, 22 de enero de 1876. 
vendedores ambulantes, amas de leche) o en negocios y talleres como asalariados (zapateros, cigarreros, modistas, cocineras). Si bien algunos miembros de la comunidad conservaban cierta independencia -más asociada con tiempos anteriores-, las formas de vida y trabajo de la mayor parte de la comunidad nos permiten identificarla como parte de la clase obrera naciente.

Asimismo, había un pequeño sector letrado en la comunidad que desempeñaba cargos de menor nivel en el Estado con sueldos más elevados o, incluso, que tenían pequeños negocios. Empero, el tener un pequeño comercio o un trabajo profesional no significaba salir de la extrema vulnerabilidad económica. Varias de estas personas, a pesar de gozar una mejor situación que el resto, cayeron en la miseria más absoluta debiendo cerrar sus negocios o pedir el auxilio de la comunidad. Es así que, incluso aquellos que tenían un negocio, ejercían un oficio simple más cercano al del artesano semiproletario que al del burgués dueño de los medios de producción que explota a los trabajadores.

Los barrios son espacios fundamentales donde se establecieron una serie de prácticas, actitudes, costumbres y relaciones que moldearon a una identidad común entre la masa trabajadora (Hoggart, 1957, pp. 4548). En un período donde la organización de tipo gremial es incipiente, aún entre los trabajadores de vanguardia, cobra más relevancia la vida social cotidiana para forjar identidades. De esta manera, los afroporteños comenzaron a agruparse en sus barrios, en cofradias y sociedades nacionales que, en los años 50 y 60, devinieron mutuales (Andrews, 1989, pp. 172-180). Las sucesivas epidemias y conflictos internos de estas décadas afectaron con particular fuerza a los trabajadores negros. Sin embargo, la "raza que se va" -en palabras de Wilde- mantuvo una fuerte y dinámica presencia en la ciudad de Buenos Aires y, especialmente, entre sus trabajadores. Se ha sostenido que la inmigración, las guerras y las epidemias (Corbière, 2003) diluyeron la presencia negra en la Argentina, pero la gran complejidad, tamaño y poder de las redes de sociabilidad afro a fin de siglo parece indicar lo contrario. La década de 1870 es testigo de un proceso de renovación en la comunidad: en estos años surgieron nuevas mutuales como Sociedad Carmen y Socorros Mutuos, Hijos del Orden, La Protectora y La Unión Proletaria. Asimismo, se erigieron algunas sociedades que nucleaban trabajadores de un mismo oficio como los Artesanos Unidos o Sociedad Cosmopolita Cigarreros de la Hoja. Por otra parte, se levantaron clubes politicos que respondian a muy diferentes tradiciones políticas. Acompañando este proceso comenzaron a publicarse decenas de revistas que, con mayor o menor longevidad, dotaron de un enorme dinamismo y vitalidad a la sociabilidad afroporteña.

No obstante, las sociedades más numerosas eran de índole cultural y 
recreativa. Si bien algunas estaban dedicadas a la llamada "alta cultura" como la Sociedad de Fomento de las Bellas Artes, predominaban aquellas vinculadas a uno de los momentos más importantes de la vida social afro: el carnaval. La relevancia de esta festividad da lugar a la creación de decenas de asociaciones musicales y carnavalescas que funcionan todo el año tales como Las Verduleras, Negras Esclavas, Negras Libres, Las Lavanderas, Raza Africana, entre otras.

Debemos considerar que el mantenimiento de estas organizaciones no era sencillo para una población obrera, significaba grandes sacrificios para quienes debian sostenerlas en un contexto de crisis. Pero los problemas económicos nunca inhibieron a los afroporteños de mantener viva su sociabilidad: cedian sus casas para hacer reuniones, las asociaciones compartian locales y, constantemente, se hacian colectas para su mantenimiento. La construcción colectiva y autónoma con respecto a los poderes hegemónicos y estatales era, sin duda, una prioridad para la comunidad afroporteña y obrera.

Finalmente, la forma en que la comunidad afroporteña se autorretrataba nos permite acercarnos a sus identidades. En primer lugar, encontramos sugerentes los nombres de algunas sociedades como Las Lavanderas, Negras Esclavas o Raza Africana, que representan no sólo su pertenencia étnica o el género femenino sino también una condición social como la esclavitud o un oficio, marcando una pertenencia a la clase trabajadora. Más revelador aún nos resulta el lenguaje de los periódicos, donde constantemente encontramos referencias a la clase obrera. Lo podemos apreciar en los títulos de los periódicos como El Proletario o, en el caso, de los semanarios La Broma, El Unionista y El Trabajo, en el subtítulo que adoptaron todos: "Órgano de las clases obreras". Asimismo, en numerosas ocasiones se halagaba a algún miembro de la comunidad afro destacando su laboriosidad o su carácter de obrero "incansable". ${ }^{4}$ Entonces, no nos sorprende que se definiera a la clase obrera como "la palanca principal del progreso". ${ }^{5}$ En cambio, frente a ellos se levantaba una burguesía descripta como una "lepra" o con insultos censurados. ${ }^{6}$

Creemos haber establecido en este apartado cómo los afroporteños formaron parte de la naciente clase obrera, tanto por sus trabajos -mayoritariamente asalariados-, sus condiciones de vida -viviendas populares en barriadas obreras-, como también por sus preocupaciones y tradiciones. Asimismo, existían situaciones diversas propias de este período transicional en el cual las relaciones sociales capitalistas no habian terminado de cristalizarse (Mitidieri y Poy, 2019, p. 8). Sin

\footnotetext{
4. "Almanaque popular", La Broma, 10 de octubre de 1878.

5. "La sociedad obrera", La Juventud, 20 de febrero de 1876.

6. "El folleto de D. Zenón", La Broma, 31 de enero de 1878.
} 
embargo, considerando tanto el sentir subjetivo como las condiciones de existencia objetivas de la comunidad afro vemos que la identidad obrera distaba de ser accidental o esporádica.

No obstante, nos parece necesario introducir dos nuevos elementos en este artículo que abarcaremos en los próximos apartados. En primer lugar, examinaremos algunos de los principales conflictos librados por la comunidad y, en segundo lugar, analizaremos la cultura afroporteña como espacio de resistencia. Al indagar en las experiencias de explotación y opresión podremos ver la forma en que se moldea una identidad común en la comunidad y, al mismo tiempo, la conformación de antagonismos fundamentales que marcan los límites de la propia identidad.

\section{Clase obrera y socialismo: las luchas de la comunidad afroporteña}

La comunidad afroporteña fue partícipe de varios conflictos a través de los años que fueron fundamentales en la formación y transformación de las identidades que atravesaban a la comunidad. Hasta el momento, es escasa la historiografia que ha investigado en profundidad la relación existente entre el movimiento negro y el surgimiento de la clase obrera y el socialismo en Argentina como tema específico.

La Comuna de París, acontecida en 1871, presentó al socialismo y a su propagadora, la Primera Internacional, como la raíz desde donde se extendian todos los males que acaecían en Europa. En Argentina, intelectuales como Miguel Cané ya veían con preocupación la relación entre los negros y el comunismo, mientras que los periódicos trataban con virulencia al marxismo (Tarcus, 2007). A pesar del contexto adverso, los afroporteños mantenían diálogos abiertos con el socialismo y las luchas libradas por la comunidad profundizaron esta relación a la vez que cristalizaban su identificación con la clase obrera.

Una primera relación con el mundo socialista y la clase obrera la encontramos en los títulos de los periódicos, la idea del proletariado como fuerza de progreso enfrentada a una burguesía parasitaria que hemos mencionado anteriormente. Asimismo, en 1876, encontramos una referencia al socialismo en La Juventud en una nota moralizante referida a la familia y la educación de las mujeres, sosteniendo que "el hombre y la mujer, ambos son formados para el socialismo con aptitudes distintas y obligaciones especiales". ${ }^{7}$ Así, se nos presenta una visión del socialismo que trascendía la esfera política para delinear una serie de valores familiares similares a los propuestos por el catolicismo. De esa forma, los periódicos afroporteños -editados por hombres-sostenían los imperativos morales sobre la mujer, su función maternal y hogareña.

7. "Un tema olvidado", La Juventud, 4 de junio de 1876. 
Este tipo de menciones al socialismo, junto a la permanente reivindicación de una identidad obrera, nos indican una afinidad por el socialismo y, particularmente, por el socialismo moderno (Andrews, 1989, p. 224). Esta afinidad entre los afroporteños, el socialismo y la clase obrera termina de cristalizarse a partir de una serie de luchas que se suceden entre 1878 y 1880: la huelga de los tipógrafos de 1878, la huelga de los cigarreros de 1879 y el boicot a los teatros racistas en 1880 .

En 1878, poco antes de la huelga tipográfica, La Juventud publicó una nota en la cual define a la Primera Internacional como la sociedad que logró organizar a los trabajadores en Europa y, a través de poderosas medidas de fuerza, obligar a los países a prestarle atención a la clase obrera. ${ }^{8}$ A pesar de reconocer estos logros, el periódico condenaba los métodos violentos y las huelgas, sosteniendo que los métodos pacíficos y la educación eran las únicas armas del progreso. Sin embargo, la oposición de La Juventud a las huelgas fue fugaz ya que en septiembre de ese mismo año decidieron apoyar las medidas de fuerza de la Sociedad Unión Tipográfica, convocando a las reuniones y asambleas, reportando sobre la situación y denunciando a las patronales por ser "ladrones de su sudor". ${ }^{9}$ Poco antes de este evento, ya La Juventud había mostrado entusiasmo por la fundación de un Centro Socialista como una "institución de obreros [que] obrara en el modo de traer la emancipación a sus asociados". ${ }^{10}$

La huelga de tipógrafos también despertó el interés de La Broma. La noticia de la protesta ocupó la primera plana del semanario y se publicó una extensa nota en apoyo a los operarios. En ésta, se denunciaban las miserables condiciones de trabajo, los bajos salarios y la tirania de los patrones, a la vez que se repudiaban las estrategias patronales para quebrar el paro, como la presencia de esquiroles. ${ }^{11} \mathrm{El}$ autor anónimo -probablemente por temor a represalias patronales-de esta nota llamaba a los obreros a organizarse en la gremial para sostener la huelga hasta la victoria. La nota finalizaba exclamando: "Siendo La Broma órgano de las clases proletarias, les envía palabras de aliento, y desea que las ideas socialistas cundan no solo entre los tipógrafos sino entre todas las clases obreras". ${ }^{12}$

De este masivo apoyo de los dos principales periódicos de la comunidad - La Juventud y La Broma- podemos extraer varios puntos de

8. "La educación de la clase obrera", La Juventud, 20 de enero de 1878.

9. "Sociedad Unión Tipográfica”, La Juventud, 30 de agosto de 1878.

10. "Asociarse para triunfar", La Juventud, 20 de octubre de 1878.

11. "El toque de alarma: la huelga tipográfica", La Broma, 5 de septiembre de 1878.

12. Ibídem. 
interés. En primer lugar, si bien habia algunos afroporteños que se desempeñaban como tipógrafos, los huelguistas eran en general foráneos a la comunidad negra. Por lo tanto, el fuerte respaldo excedía los límites étnicos y se insertaba en una red de solidaridad clasista más amplia. Asimismo, también nos resulta de gran interés el alto nivel de pertenencia política al socialismo presentado por estas dos revistas. Las referencias a los logros de la Internacional, la promoción del Centro Socialista y, principalmente, las palabras citadas de La Broma sugieren fuertemente una afinidad -usualmente ignorada- entre la comunidad afroporteña con las ideas y prácticas de los socialistas modernos.

$\mathrm{Al}$ año siguiente estalló un nuevo conflicto: la huelga de cigarreros. A diferencia del caso de los tipógrafos, la comunidad afroporteña-hombres y mujeres por igual- era empleada masivamente en los talleres de la ciudad. La medida de fuerza fue encabezada por la sociedad gremial Unión Cigarreros y, según lo informado por La Broma, la cantidad de huelguistas ascendía a 250 y habían logrado paralizar tres o cuatro fábricas. ${ }^{13}$ Los principales reclamos gravitaban en torno a mejores condiciones de trabajo, protección ante despidos y, principalmente, protección a los delegados de los talleres.

La respuesta patronal no se hizo esperar y comenzaron a reunir esquiroles para suplantar a los operarios. ${ }^{14} \mathrm{Si}$ bien la huelga finalizó con los trabajadores renunciando al pliego de reivindicaciones, Unión Cigarreros se dispuso a continuar la lucha por otros medios. La gremial organizó un taller propio para boicotear a las patronales cigarreras, ${ }^{15}$ que fue recibido con palabras de apoyo por La Broma: "Hemos tenido ocasión de provar [sic] los ricos cigarrillos de "Unión Cigarreros" -son inmejorables tanto en papel como en tabaco [...] se espenden [sic] en todos los cafés, confiterías, bares, etcétera". ${ }^{16}$ Nuevamente, sale a relucir la solidaridad entre la comunidad afro y los trabajadores huelguistas, reafirmando su pertenencia a la clase.

Finalmente, el último conflicto que queremos resaltar es aquel librado en 1880 contra las políticas racistas de los teatros. En enero de ese año, algunos teatros porteños comenzaron a prohibir la entrada a la "gente de color". Frente a esta situación, los afroporteños se nutrieron de las herramientas de la clase trabajadora y de las experiencias mencionadas para hacerles frente a los empresarios del teatro. Una de las primeras

13. "Noticias varias", La Broma, 10 de agosto de 1879.

14. "Avisos", La Pampa, 12 de agosto de 1879; "Avisos", La Prensa, 13 de agosto de 1879; "Avisos", La Prensa, 14 de agosto 1879.

15. "Taller de cigarrillos", El Nacional, 12 de agosto de 1879; "Noticias", El Porteño, 13 de agosto de 1879.

16. "Noticias varias", La Broma, 11 de octubre de 1879. 
medidas fue realizar una convocatoria hacia los teatros e ingresar por la fuerza en señal de protesta: "Si esta prohibición permaneciese, lo que la gente de color tiene que hacer es muy sencillo: -Compre su entrada y entre por la fuerza", ${ }^{17}$ seguida por un boicot a los mismos. Por otra parte, se dispusieron a organizar una movilización para el 26 de enero que fue prohibida por la policía. En paralelo, La Broma junto a la mutual La Protectora organizaron una tertulia y una colecta de firmas para conseguir el apoyo de Héctor Florencio Varela. ${ }^{18}$ Para hacerle llegar esas firmas organizaron una movilización, eludiendo las prohibiciones policiales, que logró demostrar su fuerza y, al mismo tiempo, consiguió el apoyo del intelectual. Finalmente, la presión ejercida por los afroporteños rindió sus frutos y, para evitar la escalada del conflicto, la policía y la Municipalidad levantaron la prohibición. La lección para los afroporteños se manifestó prontamente en el nuevo subtitulo de $L a$ Broma que, al finalizar el conflicto, paso a llamarse órgano de las clases obreras volviéndose heredera de la tradición iniciada con El Proletario y vinculando la identidad y la lucha étnica con la de clase.

En sintesis, estos conflictos dan cuenta que los periódicos afroporteños se solidarizaban con los reclamos de los trabajadores, tomaban parte en sus medidas de fuerza y, también, se nutrian de estas experiencias para conformar sus propias luchas mostrando que, si bien podemos distinguir analíticamente sus identidades -obreros por su clase y afrodescendientes por su etnia-, para ellos eran indisociables.

\section{La cultura del carnaval: entre la resistencia y la apropiación}

Para finalizar el trabajo, nos interesa abordar cómo se manifestó la identidad obrera dentro de las tradiciones culturales propias de los afroporteños. El campo cultural fue el escenario más permeable a los valores liberales que emanaban desde la clase dominante, dando por resultado conflictos en la propia comunidad. Si los semanarios eran el engranaje que aceitaba la maquinaria de sociabilidad afro, las sociedades culturales y recreativas eran el cuerpo más numeroso del entramado social, particularmente, aquellas vinculadas al carnaval.

La relevancia de esta festividad dio lugar a la creación de más de 20 asociaciones musicales, teatrales y carnavalescas que funcionaban todo el año. Estos grupos musicales y dramáticos ensayaban, semana tras semana, preparando sus espectáculos, realizando funciones en tertulias o salones de baile esperando febrero para salir libres y entonces la ciudad de Buenos Aires se transformaba. Desde las barriadas

17. "La gente de color", La Broma: periódico social, 17 de enero de 1880.

18. "Última hora", La Broma: periódico social, 24 de enero de 1880. 
obreras de San Telmo hasta el lejano partido de Flores, las comparsas negras -generalmente entre 50 y 100 personas- ocupaban el centro de la escena. Los disfraces, la parodia y el humor subvertían los símbolos de poder convirtiendo lo temido en motivo de risa (Bajtin, 1987, p. 74). Las calles eran inundadas por la música de las comparsas: tambores, platillos y guitarras ${ }^{19}$ eran acompañados por los cantos de los candomberos disfrazados de políticos, curas y militares, atuendos escandalosos a los ojos de la sociedad (López, 2003, p. 106). Los niños se encargaban de asaltar a toda persona (seca) con sus bombas de agua. Los faroles y las casas tampoco escapaban a la intervención y, en carnaval, amanecian adornadas. En pocas palabras, todo el barrio se convertía en un gran escenario en el cual todas las personas eran actores por el mero acto de asistir al carnaval (Bajtin, 1987, p. 7).

El carácter subversivo de la festividad despertó en los diferentes gobiernos la necesidad de disciplinar a la población. Desde 1869 los juegos con agua fueron terminantemente prohibidos por el gobierno (Guimarey, 2008, p. 11) aunque los numerosos relatos de los semanarios indican el poco éxito de la medida. ${ }^{20}$ Intelectuales liberales como Wilde repudiaron el "libertinaje" del carnaval que desafiaba no solo a la autoridad, sino también sus valores (Wilde, 1960, p. 126). Sin embargo, sus quejas no lograron censurar ni la música, ni las borracheras de la fiesta. Otros grupos aristocráticos optaron por una estrategia diferente: la apropiación de la cultura afro y su integración a las nuevas normas de sociabilidad. Un claro ejemplo de este proceso es la creación de la comparsa Los Negros en 1869 integrada por miembros de familias aristocráticas como Miguel Cané, Augusto Bullrich, entre otros. ${ }^{21}$ No obstante, ninguna fue tan insultante como las comparsas de blancos que se burlaban de los negros y sus bailes (Kordon, 1938, p. 59-60). Estas provocaron la reacción de algunos afroporteños que se sintieron humillados y decidieron retirarse del carnaval dejándolo en manos de la población blanca y "moral" (Bilbao, 1962, p. 163).

Por otra parte, dentro de la comunidad hubo una capa de intelectuales que comenzó a cuestionar fuertemente las viejas tradiciones africanas, incluyendo el uso de tambores en el carnaval, acusándolas de "semi bárbaras" propiciando, en su lugar, una nueva serie de valores morales más adecuados a la sociabilidad burguesa. ${ }^{22}$ Sin embargo, estos

19. "Varillazos", La Broma, 10 de febrero de 1879.

20. "Varillazos", La Broma, 11 de marzo de 1878.

21. "Nómina de socios", Los Negros: periódico de la sociedad del mismo nombre, 29 de agosto de 1869.

22. “QQue inocente señor!”, La Perla, 5 de enero de 1879. 
comentarios negativos sobre la propia historia afro fueron mal recibidos por la comunidad. ${ }^{23}$

Los intentos de prohibición y apropiación tuvieron un éxito muy relativo. El carnaval siguió siendo un momento de transgresión a las normas y subversión del orden establecido. Era, después de todo, el momento donde las características que en la vida cotidiana sometían al trabajador negro a la discriminación étnica y la explotación económica se volvían una razón para estar orgullosos. La identidad obrera salía a relucir cuando las murgas negras cantaban orgullosamente sobre su pobreza y se deleitaban de ser el centro de la escena: "El nombre humilde, No a todos pega, Porque es preciso, Saberlo llevar, Y en estos dias, De alegre fiesta, Cuantos ¡ihumildes!! Ser querrán". ${ }^{24}$

La fiesta era un espacio de construcción de identidad de especial importancia para los afroporteños que veían en ella una posibilidad de mantener vivas sus tradiciones y, por unos días, ocupaban un lugar central que les era vedado en la sociedad. Toda la población afro participaba del carnaval y éste se volvía una herramienta de denuncia y de motivación para hacerle frente a las desdichas cotidianas (Bajtin, 1987, p. 11). De esta manera, las tradiciones afro se configuraban como una cultura de resistencia ante los embates de la cultura hegemónica. Asimismo, las nuevas relaciones sociales capitalistas que comenzaban a cristalizarse hicieron que en el carnaval comenzase a emerger una identidad de clase vinculada a la tradición afro.

\section{Reflexiones finales}

Comenzamos este trabajo embarcándonos en la laguna historiográfica que signa al siglo XIX argentino. Hasta mitades del siglo encontrábamos una heterogénea masa de trabajadores que parecía disolverse en el aire después de la caída de Rosas solo para resurgir treinta años después como una clase obrera más o menos homogénea formada principalmente por inmigrantes. ¿Qué ocurrió en esos años intermedios? Apuntamos aquí a aportar nuevos elementos de análisis y matizar algunas afirmaciones a partir del estudio de los afroporteños.

Esta comunidad, lejos de desaparecer, formó una extensa red de organizaciones y periódicos que se prolongó a lo largo de estas tres décadas. La búsqueda constante de una organización autónoma -alejada tanto de los intereses patronales como también del Estado- fue la característica principal que marcó el accionar afro. A través de sus organizaciones establecieron debates, interactuaron con diferentes

23. "Tradiciones semibárbaras", La Perla, 15 de enero de 1879.

24. "Canciones carnavalescas", La Broma: periódico social, 6 de marzo de 1881. 
tradiciones e ideologías políticas y tomaron un rol activo en luchas políticas, étnicas y de clase. Dentro del mundo del movimiento obrero y las izquierdas, esta comunidad ocupó un papel pionero que, hasta el momento, ha sido dimensionado solo parcialmente. Desde la década de 1850 , los afroporteños levantaron su identidad proletaria junto a sus reivindicaciones étnicas, entendiendo que ambas se vinculaban. Así, se estableció una identidad proletaria-negra opuesta al burgués-blanco. El contacto con otros grupos de obreros blancos en los conventillos y en los trabajos introdujo nuevas perspectivas en la comunidad. La opresión y explotación a los trabajadores comenzó a formar parte de los debates que figuraban en las publicaciones junto a las temáticas referidas a la opresión racial. El resultado se vio plasmado en la participación activa de los afroporteños en diferentes medidas de fuerza y, también, en una creciente oposición contra la burguesía. En sintonía con esta radicalización, en la década de 1870 los principales periódicos de la comunidad adoptaron un lenguaje y una impronta proveniente del socialismo moderno. El liberalismo y el republicanismo, al no dar respuestas a las problemáticas de los trabajadores negros, fueron perdiendo lugar frente al socialismo. Las menciones al socialismo, a la Internacional y a las herramientas de la clase obrera muestran este proceso que ocurría al interior de la comunidad. Aunque el socialismo afroporteño nunca rompió todos sus lazos con el liberalismo, el republicanismo y la religión, sí demostró un enorme dinamismo en épocas donde la palabra "socialista" era repudiada en todo el mundo. A partir de lo visto en este trabajo, creemos que existen elementos para hablar de una cultura obrera, entendiéndola como un conjunto de prácticas, actitudes, creencias y costumbres políticas y culturales asociadas a una identidad obrera (Camarero, 2007, p. 219). Esta cultura se vinculaba directamente con una propia de la comunidad afroargentina y, como vimos, ambas se alimentan para dar lugar al surgimiento de una identidad afro-obrera propia.

Teniendo en cuenta estos elementos creemos que el rol de los afroporteños dentro de la historia de la clase obrera y las izquierdas en la Argentina debe explorarse en mayor profundidad. La historiografia de la clase obrera y las izquierdas, centrada en las últimas dos décadas del siglo XIX, se ha enfocado en los sectores más organizados del movimiento obrero y las izquierdas. Este recorte ha dejado a tradiciones, como la afroporteña, poco exploradas. Por su parte, la historiografia sobre la comunidad afroargentina, estableciendo un recorte más amplio, incorporó varios conceptos y temáticas fundamentales al estudiar a este actor. Sin embargo, en estos estudios, el vínculo entre los afroporteños con la formación de la clase trabajadora y el socialismo no es explorado de forma sistemática. 
De esta manera, la distancia que separa a estas corrientes -en términos conceptuales y temporales- ha derivado en que exista en la Argentina una laguna historiográfica, un área de vacancia. De cada lado de la laguna historiográfica se extiende una gran cantidad de aciertos y también de problemas. Aquí solamente apuntamos a sacar a la luz una experiencia que nos permita repensar las categorias y las formas de analizar al proletariado local para poder desenterrar los orígenes perdidos de la clase obrera en Argentina.

\section{Referencias}

Abad de Santillán, D. (1930). El movimiento anarquista en la Argentina. Desde sus comienzos hasta el año 1910. Argonauta.

Adamovsky, E. (2012). Historia de las clases populares. Sudamericana.

Andrews, G.R. (1989). Los afroargentinos de Buenos Aires. De la Flor.

Andrews, G.R. (2007). Afro-Latinoamérica, 1880-2000. Iberoamericana.

Andrews, G.R. (2010). Negritud en la nación blanca: una historia de Afro Uruguay. 1830-2010. Linardi y Risso.

Andrews, G.R. (2016). Afro-Latin America: Black Lives, 1600-2000. Harvard University Press.

Bajtin, M. (1987). La cultura popular en la Edad Media y en el Renacimiento. El contexto de François Rabelais. Alianza Universidad.

Bilbao, S.A. (1962). Las comparsas del carnaval porteño. Cuaderno del Instituto Nacional de Investigaciones Folclóricas, 3, 155-187.

Bourdé, G. (1977). Buenos Aires: Urbanización e inmigración. Huemul

Camarero, H. (2007). A la conquista de la clase obrera. Los comunistas y el mundo del trabajo en la Argentina, 1920-1935. Siglo XXI.

Cirio, N.P. (2006). La presencia del negro en grabación de tango y géneros afines. En L. Maronese (comp.). Buenos Aires negra: identidad y cultura. (pp. 25-59). CPPHC.

Cirio, N.P. (2009). Tinta negra en el gris de ayer. Teseo.

Corbière, E. (2003). El genocidio negro en la Argentina. En http://www. centroafrobogota.com / attachments / article /6/E1\%20genocidio\%20 negro\%20en\%20la\%20Argentina,\%20Emilio\%20Corblere.\%20pdf.pdf. Consultado el 20 de febrero de 2020.

Di Meglio, G. (2001). Un nuevo actor para un nuevo escenario. La participación política de la plebe urbana de Buenos Aires en la década de la Revolución (1810-1820). Boletín del Instituto Ravignani, 24, 7-41.

Falcón, R. (1984). Los orígenes del movimiento obrero (1857-1899). CEAL.

Fradkin, R.O. (2008). ¿Y el pueblo dónde está? Contribuciones para una historia popular de la revolución de independencia en el Río de la Plata. Prometeo Libros.

Frigerio, A. (2006). "Negros" y "blancos" en Buenos Aires: repensando nues- 
tras categorias raciales. En L. Maronese (comp.). Buenos Aires negra: identidad y cultura (pp. 77-98). CPPHC.

Frigerio, A. (2008). De la "desaparición" de los negros a la "reaparición" de los afrodescendientes: comprendiendo la política de las identidades negras, las clasificaciones raciales y de su estudio en la Argentina. En G. Lecchini (comp.). Los estudios afroamericanos y africanos en América Latina. Herencia, presencia y visiones del otro (pp. 117-144). Clacso. http:/ / bibliotecavirtual.clacso.org.ar/Argentina/cea-unc/20121213112425/08frig.pdf.

Geler, L. (2007). "Nuestro secso está de pie": voces afrofemeninas en la Buenos Aires de 1876-1878. Claroscuro, 6, 109-137.

Geler, L. (2008). Guardianes del progreso. Anuario de Estudios Americanos, 65 (1), 199-226.

Geler, L. (2010). Andares negros, caminos blancos: Afroporteños, Estado y Nación Argentina a fines del siglo XIX. Prohistoria Ediciones.

Geler, L. (2012). "Hijos de la patria": Tensiones y pasiones de la inclusión en la nación argentina entre los afroporteños a fines del siglo XIX. Memoria Americana, 20 (2), 273-294.

Godio, J. (1987), El movimiento obrero argentino (1870-1910). Legasa.

Guimarey, M. (2008), El Carnaval Porteño como hecho teatral urbano: estudio de las materialidades expresivas del Primer Corso Oficial de 1869. Telón de Fondo, 8, 1-31. http:/ / telondefondo.org/numeros-anteriores/ numero8/articulo/156/el-carnaval-portenio-como-hecho-teatral-urbano-estudio-de-las-materialidades-expresivas-del-primer-corso-oficial-de-1869.html.

Guzmán, F. (2006). Africanos en la Argentina: una reflexión desprevenida. Andes, 17. http://www.redalyc.org/articulo.oa?id=12701705

Hoggart, R. (1957). La cultura obrera en la sociedad de masas. Grijalbo.

Kordon, B. (1938). Candombe: contribución al estudio de la raza negra en el Rio de la Plata. Continente.

Lettieri, A. (2005). La prensa republicana de Caseros a Pavón. Secuencia, 61, 99-142. http://dx.doi.org/10.18234/secuencia.v0i61.897.

López, L. (2006). Candombe y procesos de identidad de descendientes de africanos en Buenos Aires. En L. Maronese (comp.). Buenos Aires negra: identidad y cultura (pp. 175-184). CPPHC.

López, L.V. (1882). La gran aldea. Biblioteca Virtual Universal. https:/ /www. biblioteca.org.ar/libros/70222.pdf.

Maffia, M. (2016). Migración y asociativismo de caboverdeanos en Argentina. Cadernos Ceru, 26 (1), 17-67.

Mafud, J. (1976). La vida obrera en la Argentina. Proyección.

Marotta, S. (1960). El movimiento sindical argentino. Su génesis y desarrollo. Lacio.

Mitidieri, G. y Poy, L. (2019). Presentación del dossier "Trabajadores y trabajadoras en el siglo XIX. Relaciones laborales, experiencias intelectuales, trayectorias de lucha y organización”. Archivos de historia del movimiento obrero y la izquierda, 14, 7-10. 
Oddone, J. (1949). Gremialismo proletario argentino. Libera.

Poy, L. (2014). Los origenes de la clase obrera argentina. Imago Mundi.

Romero, L.A. y Gutiérrez, L. (1990). Los sectores populares urbanos como sujetos históricos. Proposiciones, 19, 268-278.

Solomianski, A. (2003). Identidades secretas: la negritud argentina. Estudios Culturales.

Solomianski, A. (2012). "El negro Falucho" y la subalternización sistemática de los afroargentinos. En M.J. Becerra, D. Buffa, H. Noufouri, y M. Ayala (eds.). Las poblaciones afrodescendientes de América Latina y el Caribe. Pasado, presente y perspectivas desde el siglo XXI (pp. 229-247). Universidad Nacional de Cordoba.

Suriano, J. (2001). Anarquistas, cultura y politica libertaria en Buenos Aires, 1880-1910. Manantial.

Tarcus, H. (2007), Marx en la Argentina. Sus primeros lectores obreros, intelectuales y cientificos. Siglo XXI.

Tarcus, H. (2016). El socialismo romántico en el Río de la Plata. FCE.

Wilde, J. (1960). Buenos Aires desde 70 años atrás. Editorial Universitaria de Buenos Aires.

Yao, J. (2015). La prensa afroporteña y el pensamiento afroargentino a finales del siglo XIX. Historia y Comunicación Social, 20 (1), 137-157. 